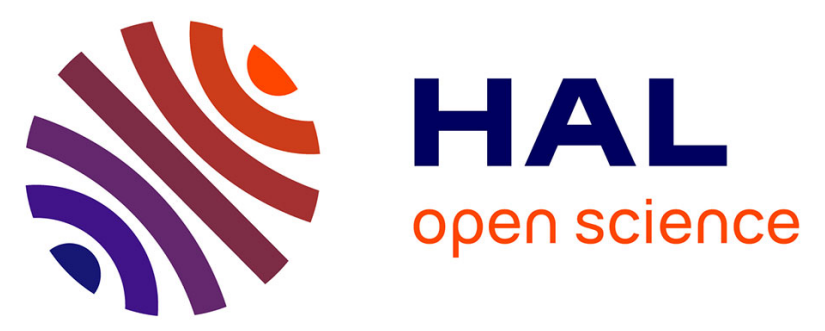

\title{
A mesofluidic multiplex immunosensor for detection of circulating cytokeratin-positive cells in the blood of breast cancer patients
}

François Breton, Bernard Bennetau, Rosette Lidereau, Laurent Thomas, Gilles Regnier, Jean-Claude Ehrhart, Patrick Tauc, Phuong-Lan Tran

\section{To cite this version:}

François Breton, Bernard Bennetau, Rosette Lidereau, Laurent Thomas, Gilles Regnier, et al.. A mesofluidic multiplex immunosensor for detection of circulating cytokeratin-positive cells in the blood of breast cancer patients. Biomedical Microdevices, 2011, 13, pp.1-9. 10.1007/s10544-010-9465-7 . hal-02428520

\section{HAL Id: hal-02428520 \\ https://hal.science/hal-02428520}

Submitted on 6 Jan 2020

HAL is a multi-disciplinary open access archive for the deposit and dissemination of scientific research documents, whether they are published or not. The documents may come from teaching and research institutions in France or abroad, or from public or private research centers.
L'archive ouverte pluridisciplinaire $\mathbf{H A L}$, est destinée au dépôt et à la diffusion de documents scientifiques de niveau recherche, publiés ou non, émanant des établissements d'enseignement et de recherche français ou étrangers, des laboratoires publics ou privés. 


\title{
A mesofluidic multiplex immunosensor for detection of circulating cytokeratin-positive cells in the blood of breast cancer patients
}

\author{
François Breton • Bernard Bennetau • \\ Rosette Lidereau • Laurent Thomas • Gilles Regnier • \\ Jean-Claude Ehrhart • Patrick Tauc • Phuong-Lan Tran
}

\begin{abstract}
We have recently reported the analytical performance of an immunosensor comprising one mm-scale parallel plate laminar flow chamber and applied to capture MCF7 breast cancer cells (Ehrhart et al., Biosens. Bioelectr. 24, 467, 2008). Herein we present a new multiplex immunosensor embodying four parallel plate laminar flow chambers that fit onto a standard, functionalized, microscopy glass slide. The four surfaces are coated with long
\end{abstract}

F. Breton · P.-L. Tran $(\square)$

CyToCap, ENS Cachan-Institut d'Alembert,

61 Avenue du Président Wilson,

94235 Cachan cedex, France

e-mail: tran@cytocap.com

B. Bennetau $\cdot$ L. Thomas

Institut des Sciences Moléculaires, UMR 5255 CNRS,

Université Bordeaux 1,

33405 Talence cedex, France

\section{R. Lidereau}

INSERM U735, Génétique Moléculaire des cancers d'origine épithéliale, Centre René Huguenin,

92210 Saint-Cloud, France

\section{G. Regnier}

UMR 8006 CNRS, Procédés et Ingénierie en Mécanique et

Matériaux, Arts et Métiers ParisTech,

151 boulevard de l'hôpital,

75013 Paris, France

J.-C. Ehrhart

UMR 8200 CNRS, Stabilité génétique et Oncogenèse, Institut Gustave Roussy, Université Paris-Sud 11,

94805 Villejuif cedex, France

P. Tauc

UMR 8113 CNRS, Biotechnologie et Pharmacologie appliquée,

ENS Cachan-Institut d'Alembert,

94235 Cachan cedex, France alkyl chain spacers of 21-aminohenicosyl trichlorosilane (AHTS) and then grafted with a monoclonal anti-human epithelial cell adhesion molecule (EpCAM) antibody specific of target cells to immobilize. We first demonstrate a significantly $(P<0.01)$ improved capacity of each of the four flow chambers of the multiplex immunosensor to capture MCF7 cells compared to the previous single chamber device. Second, in addition to an increase of cell immobilization, the multiplex device offers a versatile tool easily grafted with various purified antibodies onto the four surfaces. Third, we obtained high cell capture rate and efficiency of various numbers of MCF7 cells spiked in buffer containing an equal number of background leukocytes. And fourth, we demonstrate isolation efficiency of circulating tumor cells (CTCs) from peripheral blood drawn from a small cohort of patients with localized or metastatic breast cancer. This new multiplex immunosensor could be tested for its potential to capture different subpopulations of CTCs.

Keywords Breast cancer - Circulating tumor cells (CTCs) . Targeted cell capture - Immunosensor - Multiplex device . Long alkylsilane monolayer

\section{Introduction}

Metastasis in breast cancer patients leads to cancer-related death as early spread of tumor cells usually remains undetected at initial diagnosis on clinical, imaging, and biochemical examination. Circulating tumor cells (CTCs) are shed into blood circulation by both primary and metastatic cancers, thus their detection in a blood sample becomes of potential value despite their rarity (median, 
$\leq 1 \mathrm{CTC} / \mathrm{mL}$ ). Their isolation, enumeration and downstream functional analyses could complement existing early detection methods and have clinical significance in preventing long before the occurrence of overt metastasis. CTCs have been successfully detected and isolated from blood in patients with metastatic carcinomas (Allard et al. 2004) and were associated with the disease progression (Cristofanilli et al. 2004). A simple blood test would allow the detection and analysis of CTCs to be frequently repeated. It would also help to non-invasively stage the disease at diagnosis as well as to monitor therapy and long-term patient management (Cristofanilli et al. 2005; Hayes et al. 2006). Several reports have shown that efficacy of treatment could be measured by the number of CTCs in blood (Nolé et al. 2008; Tewes et al. 2009). CTCs provide easy access to cancer patients for performing several molecular analyses. Studies on alterations in CTC oncogenes suggested heterogeneity among cancer cells from a single patient, for example with respect to heterogeneity of HER-2 and $u P A$ gene copy number and expression in breast cancer (Cristofanilli and Mendelsohn 2006; Meng et al. 2004). Thus identifying the CTC subpopulations contained in a blood sample could help identifying targets for treatment and exploring mechanisms that underlie metastases and drug sensitivity. Increasing useful information on CTCs might help to tailor systemic therapies to the individual needs of a cancer patient.

The detection and isolation of rare CTCs in the blood of patients encountered tremendous technical challenges (Kahn et al. 2004; Krivacic et al. 2004; Racila et al. 1998; Zieglschmid et al. 2005). The most currently used methods for CTC quantitative detection include immunomagnetic separation followed by immunocytochemistry detection (Allard et al. 2004; Cristofanilli et al. 2004; Riethdorf et al. 2007; Talasaz et al. 2009) or RT-PCR to indicate the qualitative presence of CTCs in peripheral blood (Aerts et al. 2001; Iakovlev et al. 2008; Schröder et al. 2003). CTCs isolated by immunomagnetic beads coated with antibodies against the epithelial cell adhesion molecule (EpCAM) are identified by cytokeratin-positivity, DAPI nuclear staining and CD45 negativity. Other techniques such as cell filtration (Kahn et al. 2004; Wong et al. 2006) and flow cytometry (Allan et al. 2005; Cruz et al. 2005) have also been used to isolate and enumerate CTCs in blood samples.

Alternative methodologies as regards to successful isolation of viable cells, reduction of the treated blood sample volume and hands-on processing time were dealt with microfluidic procedures. CTC detection is performed on the so-called CTC-Chips made within a $967-\mathrm{mm}^{2}$ surface of 78,000 functionalized microposts coated with anti-EpCAM antibodies (Nagrath et al. 2007), in a biochip consisting of microchannels also coated with anti-EpCAM antibodies (Du et al. 2007), or in a label-free microdevice separating CTCs from blood constituents on biorheological property differences (Tan et al. 2009). Most existing techniques are associated with protocols that allow capturing only cancer EpCAM-positive epithelial cell population in peripheral blood. This could be a limiting factor and leads to missing information on cancer EpCAM-negative cell subpopulations if more than one cancer cell subpopulations are present (Sieuwerts et al. 2009). Therefore an advanced tool for detection of various breast cancer cell subpopulations for "tailored" therapy should be investigated (Cristofanilli and Braun 2010).

We recently developed a new immunosensor for breast cancer cell detection that provided improved yield of captured MCF7 breast cancer cells spiked in background leukocytes, using a parallel plate laminar flow $\mathrm{mm}$-scale chamber for fluid circulation. Design of the flow chamber at a mm-scale, hence the so-called mesofluidic designation, enables to reduce the rheological phenomena not yet well mastered in microfluidics. The surface floor is functionalized by grafting long alkyl chain spacers of 21-aminohenicosyl trichlorosilane (AHTS) followed by tethering a monoclonal anti-human epithelial cell adhesion molecule (EpCAM) antibody (Ehrhart et al. 2008; Tran and Bennetau 2004). The flow kinetics of the immunosensor is optimized for minimal shear forces and maximal contact between cells and the active surface. To further improve cell capture rate and efficiency of this mesofluidic device, we describe herein the performance of a new multiplex immunosensor embodying in parallel four parallel plate laminar flow chambers that fit onto a standard, functionalized, microscopy glass slide, with the ultimate goal of applying this methodology in a future clinical setting.

\section{Materials and methods}

\subsection{Glass surface silanization and antibody coupling}

Glass substrate and silane film preparation were performed as previously described (Ehrhart et al. 2008; Martin et al. 2005). Standard microscopy glass slides were first silanized under $\mathrm{Ar}$ atmosphere with $\mathrm{N}$-protected AHTS [N-(21trichlorosilanylhenicosyl)-phthalimide], then deprotection of the amino group of AHTS (21-aminohenicosyl trichlorosilane) was performed as described (Bennetau et al. 2000; Ehrhart et al. 2008; Martin et al. 2005).

Antibody immobilization on the silane-coated glass surface was performed with the monoclonal anti-human EpCAM antibody or the monoclonal anti-human erbB2 antibody (R\&D Systems, Lille, France) in MES-buffered saline (2-[morpholino]ethanesulfonic acid), $0.09 \% \mathrm{NaCl}$, pH 4.7 (Perbio Science, Brebières, France) at a concentration of $1 \mathrm{mg} / \mathrm{mL}$ in the presence of 1-ethyl-3-(3-dimethy- 
laminopropyl) carbodiimide hydrochloride (EDC, Perbio Science) overnight at $4^{\circ} \mathrm{C}$. All slides were then washed in PBS and stored at $4^{\circ} \mathrm{C}$ under $\mathrm{Ar}$ atmosphere up to 2 weeks until use. In negative controls, AHTS-coated surfaces were grafted with the monoclonal anti-human CD3 antibody, specific to T lymphocytes but non-specific to MCF7 cells (Dako, France). Quality controls were performed as described (Ehrhart et al. 2008).

2.2 Characteristics of laminar flow in a multiplex embodying four parallel plate laminar flow chambers

The physical characteristics of a single parallel plate laminar flow chamber of dimensions $6 \times 16 \times 0.5 \mathrm{~mm}^{3}$ $(\mathrm{W} \times \mathrm{L} \times \mathrm{H})$ were previously described (Ehrhart et al. 2008). To largely increase the cell capture surface, a new device was designed that consisted of a multiplex embodying four parallel plate laminar flow chambers (Tran et al. patent filed 2009). This device was made of a poly(methyl methacrylate) (PMMA) block bearing four cavities, each of dimensions $6 \times 16 \times 0.5 \mathrm{~mm}^{3}(\mathrm{~W} \times \mathrm{L} \times \mathrm{H})$, and sealed by a polydimethylsiloxane (PDMS) gasket against a standard microscopy glass slide $\left[26 \times 76 \mathrm{~mm}^{2}(\mathrm{~W} \times \mathrm{L})\right]$.

Figure 1 displays the simulation of progressive fluid filling of the four chambers. The circulating flow was supplied through a single channel to the entrance of the four laminar flow chambers, and the outlet of each chamber was connected to the channel of a peristaltic pump (Ismatec, Glattbrugg, Switzerland).

According to the geometry of the flow chamber, a model was constructed using the "incompressible Navier-Stokes" hypothesis of Molflow ${ }^{\circledR}$ Insight software (MPI 6.1 revision 5 , Autodesk ${ }^{\circledR}$, USA). The mesh applied was obtained using

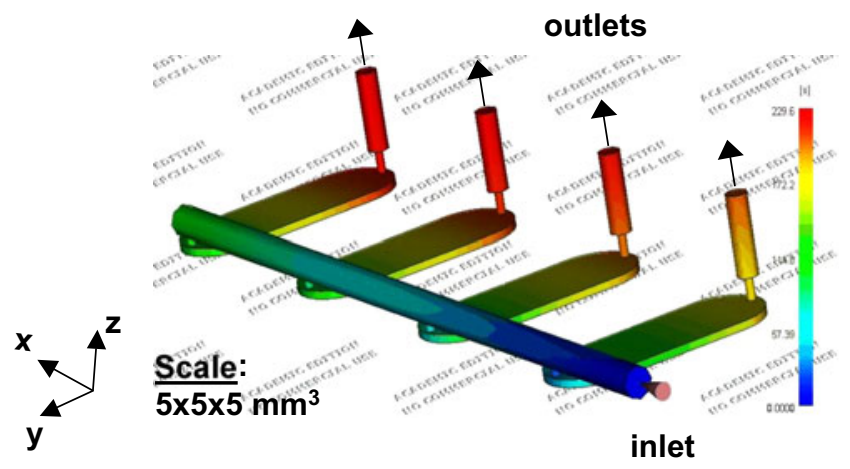

Fig. 1 Outline of the mesofluidic multiplex device embodying four parallel plate laminar flow chambers (Tran et al. patent filed 2009). A simulation of progressive fluid filling of the four mm-scale chambers is displayed. A flow rate of $90 \mu \mathrm{L} / \mathrm{min}$ was applied at the inlet, which was resolved as a flow rate of $22.5 \mu \mathrm{L} / \mathrm{min}$ per chamber. Each outlet was connected to the channel of a peristaltic pump and considered as free under atmospheric pressure. The pseudocolour progression from blue to red represents the progressive water filling the automatic mesh tool Hypermesh V8 leading to tetrahedron meshes with three nodes per side. The parameters used for this particular simulation were as follows: 1) the viscosity of water was $1.0 \times 10^{-3}$ Pa.s at $20^{\circ} \mathrm{C}$; 2) the fluid flow near the wall equals $0 ; 3$ ) a flow rate of $90 \mu \mathrm{L} / \mathrm{min}$ applied at the inlet was resolved as a flow rate of $22.5 \mu \mathrm{L} / \mathrm{min}$ per chamber, and the outlets were considered as free under atmospheric pressure. The flow in the chambers is laminar because of the low Reynolds number calculated in a suitable unit system as follows: $\mathrm{Re}=1.67 \times 10^{-5} \times \frac{Q}{\eta \eta}$, where $\mathrm{Q}$ is the flow rate $(\mu \mathrm{L} / \mathrm{min})$, 1 the flow chamber width ( $\mathrm{mm}$ ), and $\eta$ the fluid viscosity (Pa.s) (Richter et al. 1997). $\mathrm{Re}=0.0625$, when a flow rate of $22.5 \mu \mathrm{L} / \mathrm{min}$ of water at $20^{\circ} \mathrm{C}$ was applied to a 6 -mm width flow chamber. Laminar flow rate ranging from $20 \mu \mathrm{L} / \mathrm{min}$ to $1,000 \mu \mathrm{L} / \mathrm{min}$ was simulated using Molflow ${ }^{\circledR}$ Insight software and led to the same figure. A reduction to a minimum dead volume at the entrance of the flow chambers was achieved and led to rapid cell contact with the functionalized glass surfaces.

\subsection{Patient eligibility}

Patients eligible for this study were diagnosed with a localized breast carcinoma or with a metastatic adenocarcinoma of the breast (Centre René Huguenin, Saint-Cloud, France). The patient record was reviewed only to confirm the disease status, and no information on treatments or clinical course in the case of metastatic disease was abstracted.

Patients gave verbal consent to donate $15 \mathrm{~mL}$ of blood for this research study. All blood samples were drawn into Li heparinate Vacutainer tubes (Becton Dickinson, Pont de Claix, France). They were diluted into RPMI (Roswell Park Memorial Institute) medium containing $10 \%$ fetal calf serum (FCS), $2 \mathrm{mM}$ glutamine, $100 \mathrm{U} / \mathrm{mL}$ penicillin and $100 \mu \mathrm{g} / \mathrm{mL}$ streptomycin (Gibco BRL, Gaithersburg, MD, USA). Ficoll-Hypaque density gradient centrifugation was then performed at $1,600 \times \mathrm{g}$ for $20 \mathrm{~min}$ at $15^{\circ} \mathrm{C}$. The entire volume of the compartment with interphase leukocyte cells was poured into a fresh centrifugation tube. Cells were centrifuged with washing buffer at $200 \times \mathrm{g}$ for $10 \mathrm{~min}$ at $4^{\circ} \mathrm{C}$. Cells were then frozen in complete RPMI medium containing 10\% DMSO (dimethylsulfoxide) in liquid $\mathrm{N}_{2}$ for subsequent cell capture experiments.

Fresh blood samples from healthy volunteers were used as controls. Four $\mathrm{mL}$ of blood were drawn into heparin plus EDTA (ethyldiaminetetraacetic acid) Vacutainer tubes (Becton Dickinson, Pont de Claix, France). They were diluted into complete RPMI medium as described above and isolation of nucleated leukocyte cells was performed onto ACCUSPIN tubes (Sigma-Aldrich, Saint Quentin Fallavier, France) at $1,600 \times g$ for $20 \mathrm{~min}$ at $15^{\circ} \mathrm{C}$. They were washed with Hanks balanced salt solution (HBSS), 
and resuspended in HBSS plus $0.3 \%$ human serum albumin (HSA, Sigma-Aldrich) to a dilution of $10 \times 10^{6}$ cells $/ \mathrm{mL}$.

\subsection{Cell isolation in single and multiplex parallel plate} laminar flow chambers

The human breast cancer MCF7 cell line used herein underwent long-term passages $(>70)$, thus gaining high expression of HER2 (Wang and Wang 2010). Cells were grown in DMEM (Dulbecco's Modified Eagle Medium, Gibco BRL) containing 10\% FCS, $2 \mathrm{mM}$ glutamine, $100 \mathrm{U} / \mathrm{mL}$ penicillin and $100 \mu \mathrm{g} / \mathrm{mL}$ streptomycin, and cultured until subconfluence. They were then detached, washed with HBSS and resuspended in HBSS plus $0.3 \%$ HSA to a dilution of $2 \times 10^{6}$ cells $/ \mathrm{mL}$. They were then loaded in the multiplex onto four AHTS-coated glass surface grafted with the monoclonal anti-human EpCAM antibody, or in subsequent experiments using two antibodies onto two AHTS-coated glass surface grafted with the monoclonal anti-human EpCAM antibody and two AHTS-coated glass surface grafted with the monoclonal anti-human erbB2 antibody. Negative controls were performed with cells loaded onto two AHTS-coated glass surfaces alone and two AHTS-coated glass surfaces grafted with the monoclonal anti-human $\mathrm{CD} 3$ antibody specific to $\mathrm{T}$ lymphocytes but non-specific to MCF7 cells.

Optimization of cell capture was performed by running in parallel four single parallel plate laminar flow chambers, compared to the multiplex immunosensor embodying four parallel plate laminar flow chambers. We first validated the experimental criteria of the new multiplex device using MCF7 breast cancer cells spiked in buffer containing $10 \times$ $10^{6}$ leukocytes $/ \mathrm{mL}$, as reported above. Dilutions of MCF7 cells varied from 10 to $2,000 \mathrm{MCF} 7 \mathrm{cells} / \mathrm{mL}$. As previously described for a single chamber (Ehrhart et al. 2008), the following parameters were specified for the multiplex device. A flow rate of $90 \mu \mathrm{L} /$ min was applied at the inlet, which was resolved as a flow rate of $22.5 \mu \mathrm{L} / \mathrm{min}$ per chamber for driving cells into the flow chambers, until the entire active surface was covered. Then 12-min cell incubation was performed at room temperature under stable conditions. At the end of the incubation period, nonspecifically bound cells were flushed with PBS at the same flow rate of $22.5 \mu \mathrm{L} / \mathrm{min}$ per chamber for $6 \mathrm{~min}$. In another experiment with MCF7 cells, concomitant grafting of the surface floors of the multiplex with two different antibodies was also performed: two surfaces received the monoclonal anti-human erbB2 antibody, and the two remaining surfaces the monoclonal anti-human EpCAM antibody. Cell counting of all slides was performed with MATLAB software (Ehrhart et al. 2008).

Next, frozen blood samples from cancer patients and fresh blood samples from healthy donors were routinely tested using the multiplex device: blood samples from 21 patients with metastatic breast cancer, 11 patients with localized breast cancer and 16 healthy donors. The floor surfaces of the four flow chambers were coated with the monoclonal anti-human EpCAM antibody. No more extra blood samples were available for an experiment in which two surfaces could have been grafted with the anti-human EpCAM antibody and two others with the anti-erbB2 antibody. The parameters applied for isolation of CTCs were as described above. Non-specifically bound cells were flushed with PBS at the same flow rate of $22.5 \mu \mathrm{L} / \mathrm{min}$ per chamber for $6 \mathrm{~min}$.

\subsection{Immunofluorescence staining and identification of CTCs by fluorescence microscopy}

Following release of the glass slide from the multiplex device, cells were fixed with $100 \mu \mathrm{L}$ cold acetone. Cell labelling was processed with subsequent various cell markers, as previously reported (Ehrhart et al. 2008). Briefly, MCF7 cells and CTCs from human blood samples were labelled by the primary polyclonal anti-pan-cytokeratin antibody and leukocytes either by anti-CD45 allophycocyanin (APC)-conjugated IgG, or a panel of anti-CD3, -CD20 and -CD35 antibodies (Dako, France), followed by secondary anti-rabbit Alexa-conjugated IgG and anti-mouse Alexaconjugated IgG (Molecular Probes-Invitrogen, France), respectively, according to Tran et al. (1996). Cell nuclei were labelled with DAPI $(1 \mu \mathrm{g} / \mathrm{mL})$ for $5 \mathrm{~min}$.

All slides were analyzed on an inverted NIKON E50i (NIKON, France) microscope equipped with an automated stage (IMSTAR, France). Each slide containing four capture surfaces was scanned automatically in a $1360 \times 1024$ pixels format using the programmable stage and capture software (version 6, imaging IMSTAR systems, France). Captured images at $10 \times$ magnification were carefully examined and the objects that met predetermined criteria were counted. Colour, brightness and morphologic characteristics such as cell size, shape and nuclear size were considered in identifying potential tumor cells, MCF7 or CTCs, excluding cell debris, non-specific and false positive cells. The criteria for their selection were as follows: cells that stained positive by the primary polyclonal anti-pan-cytokeratin antibody and secondary Alexa-conjugated anti-rabbit IgG (green fluorescence) and met the phenotypic morphological characteristics were scored as MCF7 or CTCs; the same cells were stained by DAPI (blue stain) and negatively stained by anti-CD45-APC or anti-CD3, -CD20 and -CD35 and Alexaconjugated anti-mouse IgG (no red fluorescence).

\subsection{Statistical analysis}

All data were analyzed using a paired Student's $t$-test. 
Table 1 Significant improvement $(P<0.01)$ of MCF7 cell capture by each chamber of the multiplex device compared to that previously observed ('Ehrhart et al. 2008) with a single chamber. In both conditions, capture was performed on AHTS-coated surface glass slides grafted with the anti-human EpCAM monoclonal antibody.
Control surfaces reflect the amount of non-specific adsorption when anti-EpCAM was absent from the silane-grafted surfaces. Cell count results were obtained from three independent experiments. Values were reported as the mean \pm S.D

\begin{tabular}{|c|c|c|c|c|c|}
\hline & \multirow[t]{2}{*}{ Single flow chamber } & \multicolumn{4}{|c|}{ Multiplex embodying four flow chambers } \\
\hline & & Chamber \#1 & Chamber \#2 & Chamber \#3 & Chamber \#4 \\
\hline Cell counts for control surfaces & $223 \pm 74^{\mathrm{a}}$ & $280 \pm 65$ & $305 \pm 56$ & $292 \pm 71$ & $325 \pm 95$ \\
\hline Cell counts for AHTS-coated + anti-EpCAM-grafted surfaces & $3435 \pm 233^{\mathrm{a}}$ & $6049 \pm 333$ & $6433 \pm 245$ & $6338 \pm 352$ & $6742 \pm 410$ \\
\hline
\end{tabular}

\section{Results and discussion}

\subsection{Improvement of MCF7 breast cancer cell capture} by each chamber of the multiplex immunosensor

The new multiplex device is fabricated in a unique PMMA piece embodying four $\mathrm{mm}$-scale chambers that fits onto a standard microscopy glass slide (Section 2). Figure 1 outlines such a device showing fluid flow through the four laminar flow chambers (Tran et al. patent filed 2009). According to this design, a minimum dead volume produced at the entrance of the four chambers allows a rapid access of tumor cells to the four glass surfaces. These surfaces are functionalized by coating with long amino-silane AHTS chains followed by grafting with the monoclonal anti-human EpCAM antibody (Section 2).

The results displayed in Table 1 demonstrate an enhanced immobilization of MCF7 breast cancer cells onto the functionalized glass surfaces. A mean cell capture yield of $6391 \pm 247$ MCF7 cells per chamber in the multiplex was achieved, versus cell capture yield of $3435 \pm 233$ MCF7 cells in a single laminar flow chamber (Table 1, and Ehrhart et al. 2008). Comparing cell capture yielded by each chamber of the multiplex device to that of a single chamber,

Table 2 Comparison of MCF7 cell capture counts on four AHTScoated surfaces of the multiplex grafted with two different antibodies. Two surfaces were grafted with the anti-human erbB2 monoclonal antibody and two other surfaces with the anti-human epithelial cell adhesion molecule (EpCAM) monoclonal antibody. Cell count results were obtained from three independent experiments. The difference between MCF7 counts on both functionalized surfaces $(P<0.05)$ could be attributed to a difference in expressed erbB2 and EpCAM. Values were reported as the mean \pm S.D

Multiplex four flow chambers

AHTS-coated + anti- $\quad$ AHTS-coated + anti-

erbB2-grafted surfaces EpCAM-grafted surfaces

Chamber \#1 Chamber \#2 Chamber \#3 Chamber \#4

\begin{tabular}{lllll}
\hline Cell counts & $5044 \pm 167$ & $5055 \pm 112$ & $5710 \pm 111$ & $5890 \pm 114$
\end{tabular}

a significant difference was observed $(P<0.01)$ owing to the design of new characteristics that minimized loss of tumor cells in the dead volume.

\subsection{Versatility of antibody grafting}

Unlike a single parallel plate laminar flow chamber whereof the silanized surface was grafted with either the monoclonal
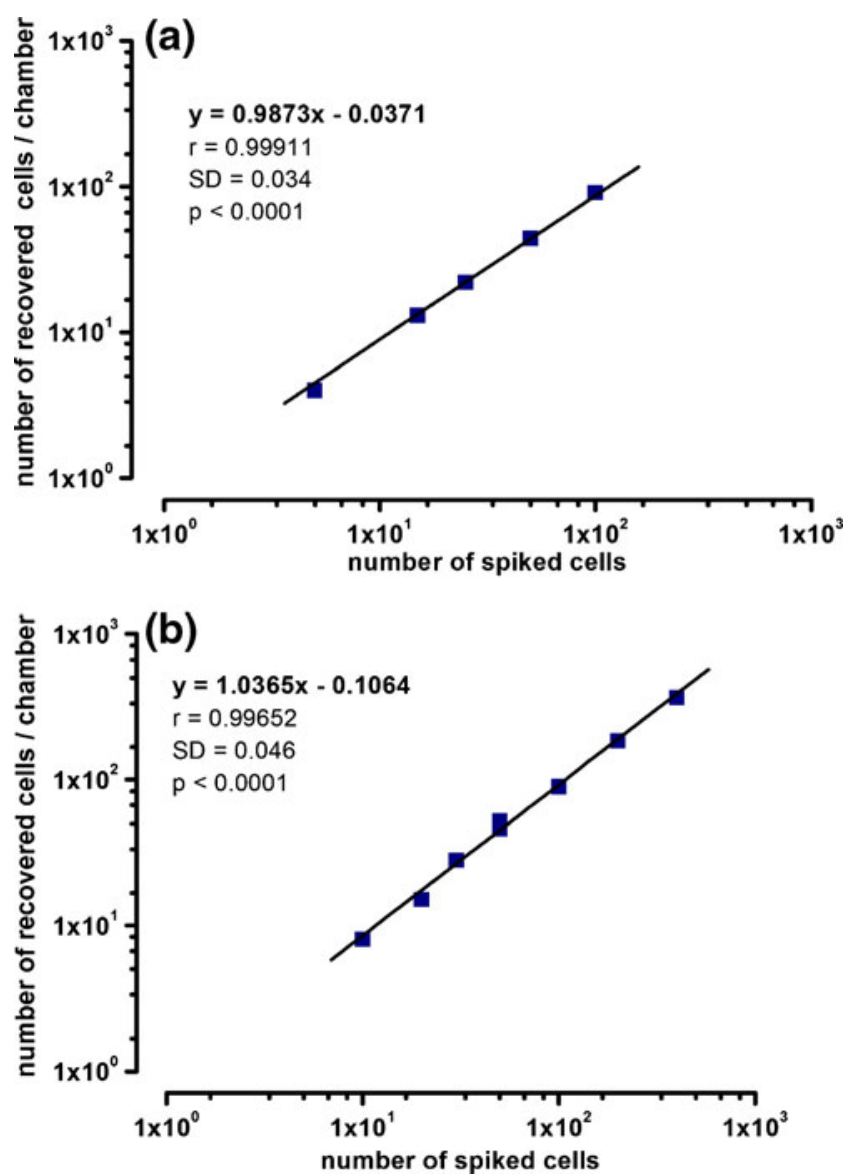

Fig. 2 (a) and (b) Regression analyses of MCF7 cell capture efficiency in single (a) and multiplex (b) parallel plate laminar flow chambers. The plots represent the number of MCF7 breast cancer cells spiked in $10 \times 10^{6}$ leukocytes $/ \mathrm{mL}$ versus the number of MCF7 cells recovered 
anti-human EpCAM antibody or the monoclonal antihuman erbB2 antibody (Ehrhart et al. 2008), the multiplex device sealed with a standard microscopy glass slide coated with long amino-silane AHTS chains allows simultaneous grafting of several antibodies. Therefore one to four different antibodies can be grafted on each AHTS-coated surface. Accordingly, the monoclonal anti-human EpCAM antibody was grafted along with the monoclonal antihuman erbB2 antibody, each antibody separately in duplicate onto two AHTS-coated surfaces. Since previous results showed the same cell distribution within and between the four chambers of the multiplex device, the order of antibodies grafting on each of the four surfaces for capturing cells expressing various surface antigens should not have any impact on cell immobilization efficiency. We took advantage of this new procedure and flowed MCF7 cells from a unique sample source (Section 2) onto differentially functionalized glass surfaces. Table 2 displays the results on MCF7 cell counts obtained with a combination of two by two antibody-grafted surfaces. The difference observed between MCF7 cell counts in surfaces functionalized with anti-erbB2 antibodies and that with anti-EpCAM antibodies, $5050 \pm 140$ versus $5800 \pm 113(P<$ 0.01 ), respectively, could be due to a difference with respect to their number of expressed receptors. Negative controls of AHTS-coated surfaces without grafting any antibody or grafted with the monoclonal anti-human CD3 antibody, non-specific to MCF7 cells, reflected the amount of non- specific adsorption in the absence of the monoclonal antiEpCAM and anti-erbB2 antibodies. Cell counts from three independent experiments yielded $415 \pm 107$ for AHTScoated surfaces alone, and $333 \pm 70$ for AHTS-coated surfaces grafted with the monoclonal anti-CD3 antibody. Hence, the multiplex device could be a potential tool for the detection of subpopulations of CTCs expressing various tumor cell markers.

\subsection{Cell capture rate and efficiency}

To evaluate tumor cell capture under physiologic conditions, we compared the capture of MCF7 human breast cancer cells spiked in blood from healthy donors by the four chambers of the multiplex to that of a single chamber. Both devices carried AHTS-coated surfaces grafted with the monoclonal anti-human EpCAM antibody. As described in Section 2, a series of various cell suspensions was performed at concentrations ranging from 10 to 2,000 tumor cells per $\mathrm{mL}$ of buffer containing $10 \times 10^{6}$ leukocytes. Immobilized cells were then submitted to staining of MCF7 cells and leukocytes and analysis for cell recovery yield (see Section 2). In cell capture experiments using a single chamber, each cell suspension concentration was loaded in a volume of $48 \mu \mathrm{L}$. Figure 2(a) displays the numbers of the MCF7 cells recovered per single chamber. In the multiplex including four chambers, each cell concentration was resuspended in a total volume of $4 \times 48 \mu \mathrm{L}$, therefore the
Fig. 3 CTC identification. High magnification $(20 \times)$ images of captured CTCs and haematologic cells from a breast cancer patient. Nuclei were stained with DAPI (a). A CTC is positively stained with the anti-pancytokeratin antibody and a secondary anti-rabbit Alexaconjugated IgG. Haematologic cells were stained with antiCD3, -CD20 and -CD35 antibodies and a secondary antimouse Texas Red-conjugated IgG. Merge image (d), arrow and insert, identifies a CTC stained positive for cytokeratin (b), and negative for haematologic cell markers (c)
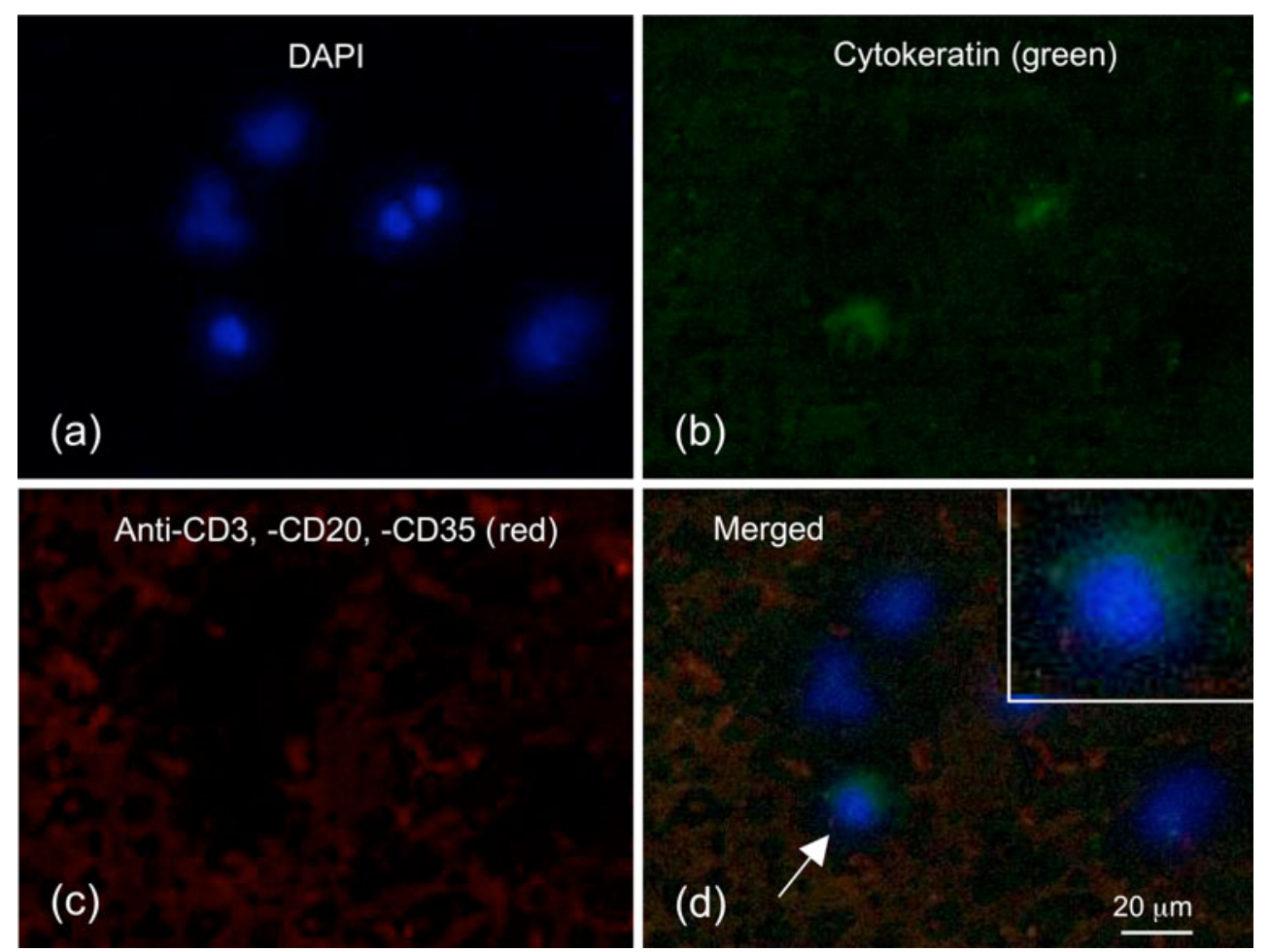
Table 3 Summary of CTC counts in $5 \mathrm{~mL}$ of blood from breast cancer patients and healthy donors. All blood samples from breast cancer patients were analyzed in triplicate and that from healthy donors in duplicate. The patient groups are sorted according to the frequency of patients with $>0$ CTC. The number and percentage of blood specimens with $>0, \geq 5, \geq 10, \geq 20, \geq 30, \geq 50$ CTCs in $5 \mathrm{~mL}$ are also provided. The sensitivity of our technique enabled identification of CTCs in three patients with localized breast cancer and $100 \%$ of the 21 patients with metastatic disease showed significant levels of CTCs $(\geq 8 \mathrm{CTCs} / 5 \mathrm{~mL})$

\begin{tabular}{lccccccccccccc}
\hline Subjects & $\begin{array}{l}\text { No. of } \\
\text { patients }\end{array}$ & $\begin{array}{l}\text { No. of analyzed } \\
\text { specimens }\end{array}$ & Range $\begin{array}{l}\text { Mean } \\
\pm \text { SD }\end{array}$ & Median & $\begin{array}{l}\text { No. } \\
(\%)>0\end{array}$ & $\begin{array}{l}\text { No. (\%) } \\
\geq 5\end{array}$ & $\begin{array}{l}\text { No. (\%) } \\
\geq 10\end{array}$ & $\begin{array}{l}\text { No. (\%) } \\
\geq 20\end{array}$ & $\begin{array}{l}\text { No. (\%) } \\
\geq 30\end{array}$ & $\begin{array}{l}\text { No. (\%) } \\
\geq 50\end{array}$ \\
\hline Healthy & 16 & 32 & $0-0$ & $0 \pm 0$ & 0 & $0(0)$ & $0(0)$ & $0(0)$ & $0(0)$ & $0(0)$ & $0(0)$ \\
Localized breast cancer & 11 & 33 & $0-5$ & $0.8 \pm 1.5$ & 0 & $3(27)$ & $1(9)$ & $0(0)$ & $0(0)$ & $0(0)$ & $0(0)$ \\
Metastatic breast cancer & 21 & 63 & $8-103$ & $39 \pm 24$ & 38 & $21(100)$ & $21(100)$ & $19(90)$ & $16(76)$ & $12(57)$ & $6(29)$ \\
\hline
\end{tabular}

results were expressed as a total number of recovered cells (Fig. 2(b)). Figure 2, (a and b), depicts a regression analysis of capture efficiency for various target cell concentrations in both devices. The recovery rate yielded from $70 \%$ to $90 \%$ in both cases. Capture rates were comparable under both conditions: $y=0.9873 \mathrm{x}-0.0371(R=0.99911)$ and $y=1.0365 x-0.1064(R=0.99652)$, respectively. In addition to high capture rates of targeted cells, only $1.8( \pm 1) \%$ of background leukocytes are observed on the capture surfaces. When compared to the recovery rate of targeted cell capture of 70-90\%, this depletion level of background cells demonstrates high capture specificity and sensitivity of our device. As expected (Table 1; Fig. 2(b)), the multiplex significantly increased the total number of detected MCF7 cells spiked in normal blood on the four functionalized surfaces $(P<0.01)$. This important characteristic will provide an advantageous performance when capture of various tumor cell subpopulations per multiplex will be required.

\subsection{Isolation of CTCs from breast cancer patients' blood}

We tested the capacity of the multiplex to capture CTCs from blood samples provided by cancer patients. A total of 128 samples from 32 patients with epithelial breast cancers and 16 healthy donors were studied. Blood specimens were collected from 21 patients with metastatic disease, 11 patients with localized disease and 16 healthy donors as controls.

Identification of CTCs on each surface capture of the multiplex consisted of staining with 4,6-diamino-2-phenylindole (DAPI) for DNA content, anti-pan-cytokeratin antibodies for epithelial cells, and either anti-CD45 or a cocktail of anti-CD3, -CD20, -CD35 antibodies for haematologic cells (Fig. 3(a-d)). Captured cells staining positive for cytokeratin and negative for haematologic markers were recorded as CTCs. The morphologic characteristics exhibited by the captured CTCs were consistent with malignant cells, including large cellular size with high nuclear:cytoplasmic ratios (Fig. 3(d) and insert). The cell viability of captured cells was assessed under transmission light using Trypan blue that attested integrity of the cell membrane.

Table 3 displays the number of blood specimens tested for CTCs from patients with localized breast cancer and patients with metastatic breast cancer. All blood samples from breast cancer patients were analyzed in triplicate and that from healthy donors in duplicate. The number of CTCs ranged from 8 to 103 per $5 \mathrm{~mL}(39 \pm 24$, mean \pm S.D.; median, 38) for metastatic breast cancer and 0 to $5(0.8 \pm$ 1.5, mean \pm S.D.; median, 0 ) among localized breast cancer. None of the 16 healthy donor blood samples had any identifiable CTC. The patient groups in Table 3 are sorted according to the frequency of patients with $>0$ CTC. The number and percentage of blood specimens with $>0, \geq 5$, $\geq 10, \geq 20, \geq 30, \geq 50 \mathrm{CTCs}$ in $5 \mathrm{~mL}$ are provided. The sensitivity of our technique enabled identification of CTCs in three patients with localized breast cancer $(3 / 11,27 \%)$ and $100 \%$ of the 21 patients with metastatic disease showed

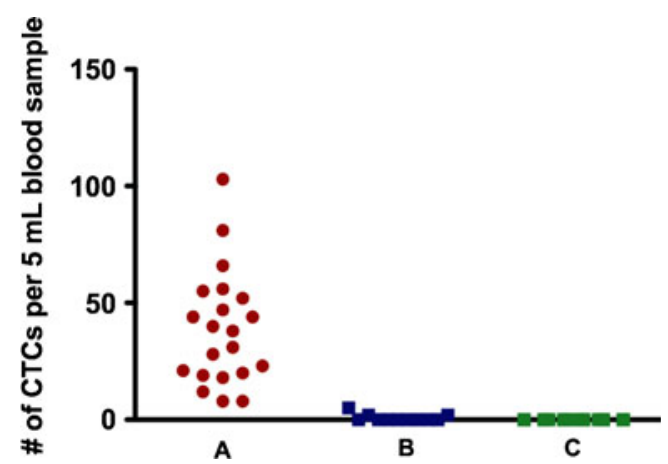

Fig. 4 Prevalence of CTCs in $5 \mathrm{~mL}$ of blood from breast cancer patients and healthy donors. All blood samples were processed as described in Section 2. CTC captures were performed on glass slides coated with long amino-silane chains, AHTS, and grafted with the anti-human EpCAM antibody using the multiplex immunosensor embodying four parallel plate laminar flow chambers. (a) frequency of CTCs per $5 \mathrm{~mL}$ blood sample in patients with metastatic breast cancer (red circle). (b) frequency of CTCs per $5 \mathrm{~mL}$ blood sample in patients with localized breast cancer (blue square). (c) absence of CTCs per $5 \mathrm{~mL}$ blood sample in control healthy donors (green square) 
significant levels of CTCs $(\geq 8 \mathrm{CTCs} / 5 \mathrm{~mL})$. A clear difference between numbers of CTCs detected in the groups of metastatic breast cancer and those of localized breast cancer demonstrated high sensitivity and selectivity provided by functionalized glass surfaces coated with long alkylsilane chains AHTS and grafted with purified antihuman EpCAM antibody (Fig. 4).

\section{Conclusion}

Designing a mesofluidic strategy with four parallel plate laminar flow chambers aims optimization at a mm-scale of the detection of rare cells in a complex body fluid. That procedure enables higher detection sensitivity due to lower dead volume, reduction in rheological phenomena not yet well mastered in microfluidics, and the design of a user-friendly and non-invasive medical device for in vitro diagnosis (Tran and Bennetau 2004; Tran et al. 2009). Here we demonstrate the analytical performance of this new immunosensor applied to gently immobilize breast cancer CTCs utilizing antibody grafted on long alkylsilane-coated glass surface. The device allows high sensitivity and specificity for capture and purification of large numbers of viable CTCs. Additional to an optimization of CTC immobilization, the multiplex immunosensor offers a versatile tool readily grafted with various purified antibodies. The surfaces of such a device can be grafted with up to four different purified antibodies, enabling the potential detection of various subpopulations of CTCs. Another important feature of the multiplex immunosensor is its active glass surface that provides an ideal transparent surface easy to read under fluorescence microscopy. Then recovered glass surfaces can be easily processed for further cellular, genetic and biochemical analyses. To the best of our knowledge, this is the first tool that allows performing various protocols from cell immobilization on a functionalized glass slide to downstream analyses on the same stand.

Acknowledgements The authors thank Pr. Joseph Zyss, head of the Institut d'Alembert, for supporting this project, Julie Morisot for technical assistance and Dr Helise Stabile for initiating automated image acquisition. They also thank the laboratory SATIE UMR 8029 CNRS (Systèmes et Applications des Technologies de l'Information et de l'Energie) for providing computing means. This study was supported by the Agence Nationale de la Recherche (grant \#ANR-EMPB CAPCELL 2006-06).

\section{References}

J. Aerts, W. Wynendaele, R. Paridaens, M.R. Christiaens, W. van den Bogaert, A.T. van Oosterom, F. Vandekerckhove, Ann. Oncol. 12, 39 (2001)
A.L. Allan, S.A. Vantyghem, A.B. Tuck, A.F. Chambers, I.H. ChinYee, M. Keeney, Cytom. A 65, 4 (2005)

W.J. Allard, J. Matera, M.C. Miller, M. Repollet, M.C. Connelly, C. Rao, A.G. Tibbe, J.W. Uhr, L.W. Terstappen, Clin. Cancer Res. 10, 6897 (2004)

B. Bennetau, J. Bousbaa, F. Choplin, CNRS, FR00/00695 (2000)

M. Cristofanilli, J. Mendelsohn, Proc. Natl. Acad. Sci. USA 103, 17073 (2006)

M. Cristofanilli, S. Braun, JAMA 303, 1092 (2010)

M. Cristofanilli, G.T. Budd, M.J. Ellis, A. Stopeck, J. Matera, M.C. Miller, J.M. Reuben, G.V. Doyle, W.J. Allard, L.W. Terstappen, D.F. Hayes, N Engl J. Med. 351, 781 (2004)

M. Cristofanilli, D.F. Hayes, G.T. Budd, M.J. Ellis, A. Stopeck, J.M. Reuben, G.V. Doyle, J. Matera, W.J. Allard, M.C. Miller, H.A. Fritsche, G.N. Hortobagyi, L.W. Terstappen, J. Clin. Oncol. 23, 1420-30 (2005). Erratum in J. Clin. Oncol. 23, 4808 (2005)

I. Cruz, J. Ciudad, J.J. Cruz, M. Ramos, A. Gómez-Alonso, J.C. Adansa, C. Rodríguez, A. Orfao, Am. J. Clin. Pathol. 123, 66 (2005)

Z. Du, K.H. Cheng, M.W. Vaughn, N.L. Collie, L.S. Gollahon, Biomed. Microdevices 9, 35 (2007)

J.C. Ehrhart, B. Bennetau, L. Renaud, J.P. Madrange, L. Thomas, J. Morisot, A. Brosseau, S. Allano, P. Tauc, P.L. Tran, Biosens. Bioelectr. 24, 467 (2008)

D.F. Hayes, M. Cristofanilli, G.T. Budd, M.J. Ellis, A. Stopeck, M.C. Miller, J. Matera, W.J. Allard, G.V. Doyle, L.W. Terstappen, Clin. Cancer Res. 12, 4218 (2006)

V.V. Iakovlev, R.S. Goswami, J. Vecchiarelli, N.C. Arneson, S.J. Done, Breast Cancer Res. Treat. 107, 145 (2008)

H.J. Kahn, A. Presta, L.Y. Yang, J. Blondal, M. Trudeau, L. Lickley, C. Holloway, D.R. McCready, D. Maclean, A. Marks, Breast Cancer Res. Treat. 86, 237 (2004)

R.T. Krivacic, A. Ladanyi, D.N. Curry, H.B. Hsieh, P. Kuhn, D.E. Bergsrud, J.F. Kepros, T. Barbera, M.Y. Ho, L.B. Chen, R.A. Lerner, R.H. Bruce, Proc. Natl Acad. Sci. USA 101, 10501 (2004)

P. Martin, S. Marsaudon, L. Thomas, B. Desbat, J.P. Aimé, B. Bennetau, Langmuir 21, 6934 (2005)

S. Meng, D. Tripathy, S. Shete, R. Ashfaq, B. Haley, S. Perkins, P. Beitsch, A. Khan, D. Euhus, C. Osborne, E. Frenkel, S. Hoover, M. Leitch, E. Clifford, E. Vitetta, L. Morrison, D. Herlyn, L.W. Terstappen, T. Fleming, T. Fehm, T. Tucker, N. Lane, J. Wang, J. Uhr, Proc. Natl Acad. Sci. USA 101, 9393 (2004)

S. Nagrath, L.V. Sequist, S. Maheswaran, D.W. Bell, D. Irimia, L. Ulkus, M.R. Smith, E.L. Kwak, S. Digumarthy, A. Muzikansky, P. Ryan, U.J. Balis, R.G. Tompkins, D.A. Haber, M. Toner, Nature 450, 1235 (2007)

F. Nolé, E. Munzone, L. Zorzino, I. Minchella, M. Salvatici, E. Botteri, M. Medici, E. Verri, L. Adamoli, N. Rotmensz, A. Goldhirsch, M.T. Sandri, Ann. Oncol. 19, 891 (2008)

E. Racila, D. Euhus, A.J. Weiss, C. Rao, J. McConnell, L.W. Terstappen, J.W. Uhr, Proc. Natl Acad. Sci. USA 95, 4589 (1998)

M. Richter, P. Woias, D. Weiß, Sens. Actuators, A. 62, 480 (1997)

S. Riethdorf, H. Fritsche, V. Müller, T. Rau, C. Schindlbeck, B. Rack, W. Janni, C. Coith, K. Beck, F. Jänicke, S. Jackson, T. Gornet, M. Cristofanilli, K. Pantel, Clin. Cancer Res. 13, 920 (2007)

C.P. Schröder, M.H. Ruiters, S. de Jong, A.T. Tiebosch, J. Wesseling, R. Veenstra, J. de Vries, H.J. Hoekstra, L.F. de Leij, E.G. de Vries, Int. J. Cancer 106, 611 (2003)

A.M. Sieuwerts, J. Kraan, J. Bolt, P. van der Spoel, F. Elstrodt, M. Schutte, J.W.M. Martens, J.-W. Gratama, S. Sleijfer, J.A. Foekens, J. Natl Cancer Inst. 101, 61 (2009)

A.H. Talasaz, A.A. Powell, D.E. Huber, J.G. Berbee, K.-H. Roh, W. Yu, W. Xiao, M.M. Davis, R.F. Pease, M.N. Mindrins, S.S. Jeffrey, R.W. Davis, Proc. Natl Acad. Sci. USA 106, 3970 (2009)

S.J. Tan, L. Yobas, G.Y. Lee, C.N. Ong, C.T. Lim, Biomed. Microdevices 11, 883 (2009) 
M. Tewes, B. Aktas, A. Welt, S. Mueller, S. Hauch, R. Kimmig, S. Kasimir-Bauer, Breast Cancer Res. Treat. 115, 581 (2009)

P.L. Tran, B. Bennetau, FR04 07722, CNRS/ENS Cachan/Univ. Bordeaux I, Patent WO200616044 (2004)

P.L. Tran, J. Weinbach, P. Opolon, G. Linares-Cruz, J.P. Reynes, A. Grégoire, E. Kremer, H. Durand, M. Perricaudet, J. Clin. Invest. 99, 608 (1996)
P.L. Tran, G. Régnier, F. Breton, Newly filed invention, CNRS-ENS Cachan patent application (2009)

L. Wang, Z.-Y. Wang, Oncol. Rep. 23, 1109 (2010)

N.S. Wong, H.J. Kahn, L. Zhang, S. Oldfield, L.Y. Yang, A. Marks, M.E. Trudeau, Breast Cancer Res. Treat. 99, 63 (2006)

V. Zieglschmid, C. Hollmann, O. Böcher, Crit. Rev. Clin. Lab. Sci. 42, 155 (2005) 